In line with regulations adopted internationally, this law establishes basic rules for the treatment of individuals. Importantly, it sets out a series of definitions, of the following terms: mental health; mental disorders; mental illness; mental capacity; consultant psychiatrist; treating physician; the guardian; voluntary admission; compulsory admission; home leave; and mandatory community treatment order. It also sets out the role of the 'Competent Entity': the Competent Entity will supervise and monitor the implementation of the Mental Health Law, inspect approved healthcare services, consider appeals from patients and their families, discharge patients from compulsory admission and assign guardians.

The articles of the law cover: the rights of people who are mentally ill; compulsory admission for treatment; temporary compulsory admission for treatment; compulsory admission for the purpose of assessment; termination of compulsory admission; home leave; mandatory community treatment orders; compulsory readmission; admission by judicial order or court sentence; termination of admission by judicial sentence; transfer of patients to other institutions; and penalties for physicians who violate the human rights of people who are mentally ill.

\section{Conclusions}

While there has not been a mental health act in Qatar, the provisions of common law have enabled mental health professionals to provide appropriate treatment and care for people who are mentally ill under compulsory conditions with the support of the courts and the police and, importantly, the patients' families. The long-awaited Mental Health
Law has been drafted in the context of the National Mental Health Strategy. The vision of the Strategy is to protect, promote and enhance the mental health of all the people of Qatar. The legislation will incorporate provisions on the rights of persons with mental disorders and disabilities. The Mental Health Law is soon due to receive assent. It draws upon international mental health laws and best practice, including the Mental Health Act 2007 in England and Wales and the new Egyptian legislation (Loza \& El Nawawi, 2012). Its provisions are complimented by executive by-laws (codes of practice).

No doubt the new Law will be tried and tested in practice and may need amendment and reform (as has the Egyptian Mental Health Act). The introduction of the Law will encourage other countries in the Eastern Mediterranean Region to follow suit and develop mental health legislation, as recommended in the Regional Mental Health Strategy (World Health Organization, 2011) and the World Health Organization Global Comprehensive Mental Health Strategy.

\section{References}

Abou-Saleh, M. T. (2012) The World Federation for Mental Health building its constituency in the East Mediterranean Region for improving care and the lives of the mentally ill and their families. Arab Journal of Psychiatry, 23, 178-184.

El-Islam, M. F. (1978) Transcultural aspects of psychiatric patients in Qatar. Comparative Medicine East and West, 6, 33-36.

Loza, N. \& El Nawawi, M. (2012) Mental health legislation in Egypt. International Psychiatry, 9, 64-66.

World Health Organization (2011) Strategy for Mental Health and Substance Abuse in the Eastern Mediterranean Region 2012-2016. See http://applications.emro.who.int/docs/RC technical papers_2011_5_14223.pdf (accessed September 2013).

\title{
MENTAL HEALTHLAW \\ Mental health law in Jordan
} PROFILE

\author{
Walid Sarhan ${ }^{1}$ FRCPsych and Ali Alqam² MRCPsych
}

${ }^{1}$ Consultant Psychiatrist, Amman, Jordan, and Editor of the Arab Journal of Psychiatry. email sarhan34@orange.jo ${ }^{2}$ Consultant Psychiatrist, Amman, Jordan, and Assistant Editor of the Arab Journal of Psychiatry. email alialqam7777@gmail.com
The history of the psychiatric scene in Jordan is briefly described, and the Jordanian Public Health Law is highlighted, as its chapter on mental health regulates compulsory admission. Some notes are included on the criminal law and civil law, and Jordan's forensic psychiatric services are briefly described.

Jordan was served until 1967 by Bethlehem Hospital in the West Bank, Palestine, a hospital that was established in the 1930s, during the British colonial period. In 1967 the East Bank of the
Kingdom was left without a psychiatric hospital. Soon after that, a psychiatric hospital dealing with severe mental illness was established in Amman and the Royal Military Medical Services started a comprehensive in-patient and out-patient department at King Hussein Medical Centre. At the same time, the Ministry of Health expanded out-patient services. Soon after that, a few private psychiatric clinics were opened, and in 1996 the first private teaching psychiatric hospital was established.

There is only one forensic unit in Jordan, the National Centre for Mental Health; there are no units in prisons, but psychiatrists visit prisons 
regularly, and they write reports to the courts about fitness to plead, criminal responsibility and competence.

\section{Mental health provisions in public health law}

For decades, Jordan did not have a mental health act. Common law gave psychiatrists the authority, at the request of the family, to admit patients or to treat them against their will. It was only in 2008, with the implementation of Public Health Law No. 47 , that psychiatric care came to be governed by statute. Chapter 4 of that law concerns mental health. It has four parts:

\section{Part 1}

This part mandates that patients with a mental illness or addiction be admitted to a psychiatric hospital or a psychiatric unit in a general hospital that is equipped with everything necessary for the safety of the patient, and that is staffed by a mental health team. This has stopped the previous practice of admitting such patients on general hospital medical wards.

\section{Part 2}

This part governs voluntary and involuntary admissions to psychiatric hospitals and units. The law describes three reasons for the compulsory admission of patients with a mental illness or addiction:

- their condition requires in-patient treatment

- they present a danger to themselves or others (danger can be in the form of a risk of either physical or verbal aggression)

- there is a court order for admission.

In relation to the first two, the family (next of kin) has to apply to the hospital director, and there needs to be a psychiatric report supporting the application. Admission proceeds once the approval of the director of the hospital is obtained.

\section{Part 3}

This part specifies that the Minister of Health has the authority to ask a committee to review a case where there is a complaint about psychiatric care. Accordingly, the Minister has the authority to stop the admission or discharge of the patient, except where admission was by court order.

\section{Part 4}

Following improvement in the health of the patient, the treating psychiatrist, with the approval of the hospital director, will inform the family about the date of discharge, except if the patient was admitted through a court order, in which case the court will be informed about the readiness of the patient for discharge.

\section{Mental health in criminal law}

The criminal law is still based on the British McNaughton rule: offenders are considered either sane or insane, and if insane are committed to the Forensic Unit of the National Centre for Mental Health until they are completely cured. The issue of cure is controversial, as application of the criminal law in this regard has led to injustice; for example, some patients with schizophrenia are maintained on treatment for years, with very little chance of being discharged, despite full remission. Furthermore, court procedures are stopped when a patient is deemed unfit to plead, for example because of an intellectual disability; such patients may then remain in hospital for the rest of their lives, even without having been found guilty in court.

\section{Mental health in civil law}

In guardianship, divorce and child custody cases people suspected of having mental health problems are not routinely referred for psychiatric evaluation; it is up to the judge to decide whether the person is sane or not.

\section{Psychiatric disorders in Jordanian law}

Beyond Public Health Law No. 47, neither psychiatric disorders nor psychiatry are mentioned in any other Jordanian legislation, except for one law that deals with court procedure, where the terms 'insanity' and 'chronic illness' are used and psychiatrists are requested to deal with relevant issues in court in cases relating to guardianship, criminal responsibility and mental capacity.

\section{Discussion}

The implementation of the mental health provision in the Public Health Law since 2008 has been working well, as most of our patients are cared for in the community, by their families - even patients who are severely ill. The majority of admissions are done on a voluntary basis, with the help of the families. The majority of psychiatrists in Jordan do not see the need for more sophisticated mental health legislation, but would like some amendments to the law. In the authors' opinion, the addition of safeguarding provisions in relation to the patients' rights would be desirable, as would measures for the protection of psychiatrists.

The main problem facing psychiatrists in Jordan is the way in which psychiatric patients are dealt with by the legal system. Psychiatrists are called upon as witnesses but not specifically as experts, and the legal explanation given is that psychiatrists are witnesses in relation to any reports they prepare. The qualifications and experience of the psychiatrist are not necessarily taken into consideration, because psychiatrists are not mentioned in any law. Judges can therefore give whatever weight they choose to professional psychiatric opinion. 